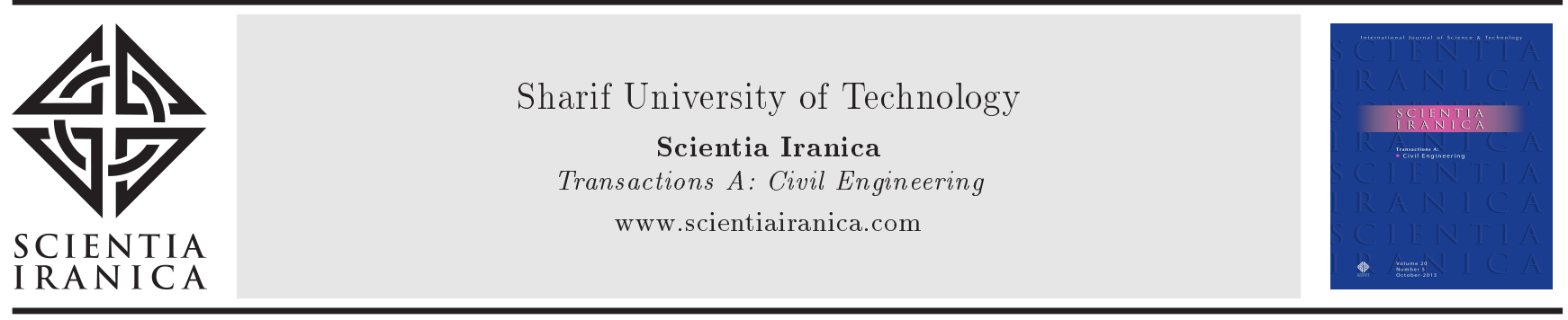

\title{
Strain rate effect on the mesoscopic modeling of high-strength steel fiber-reinforced concrete
}

\author{
S. Mehrpay and R.S. Jalali* \\ Department of Civil Engineering, Faculty of Engineering, University of Guilan, Rasht, P.O. Box 3756 , Iran.
}

Received 31 May 2015; received in revised form 21 November 2015; accepted 30 May 2016

\section{KEYWORDS}

Meso-scale;

SFRC;

SHPB;

High strain rate;

Impact.

\begin{abstract}
The research, presented in this paper, aims to investigate the behavior of a High-Strength Steel Fiber-Reinforced Concrete (HSSFRC) mesoscopic finite element model at compressive high strain rates. In order to produce a three-dimensional meso-scale finite element model, a computer code is developed to randomly produce mesoscopic models of SFRC specimen. The specimen is assumed to be reinforced by 0.6 percent volume fraction of hooked steel fibers (Dramix RC-65/35-BN) with random positions and orientations. Aggregates of the compound are assumed to have spherical shape and are produced according to Fuller grading curve. Based on the initial mesoscopic model, a finite element model is produced and used in an explicit dynamic simulation. The contribution of inertial confinement to the dynamic strength enhancement of concrete at high strain rates was investigated, and its effective role was observed. Accordingly, defining a Dynamic Increase Factor (DIF) for mortar matrix led to overestimation; nevertheless, the inertial confinement by itself could not justify the increment of specimen strength under the dynamic loading. Obtained results also show that steel fibers have a negligible influence on the strength, strength enhancement ratio (DIF), and post-peak behavior of the model at high strain rates.

(C) 2017 Sharif University of Technology. All rights reserved.
\end{abstract}

\section{Introduction}

It is well known that the strength of concrete improves at high strain rate loadings. Considering its versatile usages in building constructions, this property has made the concrete an appropriate material for structures that are designed to endure challenging situations. In order to aid in designing such structures, numerical models are occasionally made to simulate the behavior of the structure or a part of it under difficult situations. Although these models usually implement complicated constitutive models, but most of them consider concrete as a homogenous material. Some studies show that in specific situations, a non-

*. Corresponding author. Tel: +98133369 0270;

Fax: +981333690271

E-mail address: saleh@guilan.ac.ir (R.S. Jalali) homogenous concrete model may lead to a better simulation. Concrete is a porous material, made up of cemented particles with various diameters from aggregates to fine powder size. Modeling such a complicated material can be an expensive challenge. Mesoscopic simulation of concrete is a common method for considering concrete as a heterogeneous material whilst avoiding mentioned complexity. In the mesoscale modeling, concrete is considered as a substance made up of homogenous phases. Main phases of a mesoscopic concrete model are aggregates and mortar matrix which embed aggregates. The studies indicate that a weak zone is manifested around the aggregates of concrete; in order to consider this weak ring of the chain, an interfacial phase should be considered between aggregate and mortar phases, which is referred to as Interfacial Transition Zone or abbreviated as ITZ. Thus, in mesoscopic modeling of concrete, rather 
than dealing with a mixture of particles and packing problems and mixture void, it would be sufficient to deal with a de-layered compound typically made up of two or three homogenous phases (mortar matrix, aggregates, and ITZ).

While the concrete is infamous for its post-peak behavior, high-strength concrete is associated with a more brittle failure in comparison to the conventional concrete. Addition of steel fibers is a common method for ameliorating post-peak behavior of high-strength concrete.

This research aims to investigate the behavior of a three-dimensional mesoscopic model of HSSFRC specimen at high strain rates. Studies in this field can not only aid in developing the methods used to simulate concrete, but also contribute to the understanding of the behavior of this material in different situations.

As already mentioned, the strength enhancement of concrete-like materials under high-strain rate loading is well known. Researchers have not reached a consensus on factors influencing this strength enhancement at high strain rates. The inertial confinement is known as one of the parameters that plays role in the mentioned phenomenon. Since inertia resists against the lateral deformation of the specimen or concrete member, it will enforce some sort of confinement that will result in higher strength of the material. In 1986, Bischoff and Perry [1] not only reported the effect of strain rate on the strength, but also on the strain of the specimen at maximum compressive stress (critical strain). Later in 1991, Bischoff and Perry [2] gathered scattered reported data on the response of concrete under dynamic loading with different strain rates. In addition to the inertial confinement, Bischoff and Perry mentioned the formation of micro-cracks at higher strain rates as a factor that will result in the higher strength of concrete, since at higher strain rates, cracks will not necessarily form in weaker areas of concrete. In 1990, Harsh et al. [3] studied the effect of strain rate on the behavior of mortar and cement paste. In addition to the enhancement in the compressive strength of the specimens, they observed an increase in initial modulus of elasticity and initial Poisson ratio at higher strain rates.

In 2000, Le Nard and Bailly [4] simulated a compressive dynamic test on concrete specimen using finite element method. In order to simulate concrete specimen beside a plastic material model based on Otosen criterion, they tried a viscoplastic material model. In their research, Nard and Bailly concluded that inertial confinement is the primary factor in the strength enhancement of concrete at high strain rates.

Lok et al. [5], in 2003, investigated the behavior of steel fiber-reinforced concrete specimens under dynamic uniaxial compression and tension using SHPB test. In this test, Kolsky apparatus had bar diameter of
$75 \mathrm{~mm}$. According to the results they obtained, Lok et al. concluded that at very high strain rates, especially at strain rates higher than $100 \mathrm{~s}^{-1}$, SFRC specimens lacked expected ductility.

In 2004, Lok and Zhao [6] performed similar experiments on SFRC specimens reinforced with 0.6 percent volume fraction of hooked steel fibers. The obtained results showed that at strain rates higher than $50 \mathrm{~s}^{-1}$, steel fibers would not enhance ductility of the specimen.

In 2008, Zhou and Hao [7] used a mesoscopic axisymmetric model based on Drucker-Prager criterion to investigate the behavior of concrete-like materials under high strain rates. They observed that in their models, the influence of inertial confinement on strength enhancement of specimen was negligible for strain rates under $200 \mathrm{~s}^{-1}$.

In 2010, Kim et al. [8] used finite element modeling in an attempt to gain a better understanding of the factors influencing SHPB test results. They concluded that friction between specimen and pressure bar will contribute to the strength enhancement at high strain rates. In addition, strain rate effect may be doublecounted in rate-sensitive material models.

In 2012, $\mathrm{Xu}$ et al. [9] used a two-dimensional axisymmetric mesoscopic model of SFRC specimen in order to simulate an SHPB setup similar to the test performed by Lok an Zhao [6]. Although axisymmetric modeling may exaggerate the confinement effect imposed by steel fibers, obtained results could predict the DIF of SFRC specimen at different strain rates very well.

In 2013, Fang and Zhang [10] used a finite element model consisting of homogenous concrete and randomly distributed fibers (modeled by truss elements) to simulate several experiments. They also used tie-break contact algorithm to simulate debonding and sliding of the fibers inside the concrete. They observed good agreement between numerical results obtained from their model and the test results.

In 2013, Hao et al. [11] performed a hierarchy of SHPB tests on concrete specimens in order to investigate the influence of different factors on the outcome of the tests. According to their research, the confinement imposed by the friction force between specimen and the bars of Kolsky set up can increase the strength of the specimen. Also, Hao et al. observed that the addition of aggregate would amplify effect of the inertial confinement. They also concluded that inertial confinement effect depends on the size of the specimen.

Some of the previous researchers have employed two-dimensional mesoscopic models to investigate steel fiber reinforced concrete in high strain rates (e.g., $[9,12])$. This research tries to present a more realistic three-dimensional mesoscopic finite element model of 
high-strength steel fiber-reinforced concrete, and investigate how well this model can simulate the behavior of a similar SHPB test specimen in different compressive strain rates, and how the steel fibers and aggregates can affect the stress distribution, strength enhancement, and the behavior of the model. In addition, the effect of implementing a rate sensitivity curve and inertial confinement is investigated. Simulations in this study are performed by employing an LS-Dyna hydrocodebased FE package that provides numerous advanced material models for simulating concrete-like materials in explicit dynamic analysis, which is appropriate for simulating high strain rate problems. Dimensions and properties of the specimen are extracted from the work of Lok and Zhao [6]. Accordingly, the model is assumed to be reinforced with $0.6 \%$ (volume fraction) of hooked steel fibers (RC-65/35-BN). Steel fibers are distributed randomly among the aggregates (Figure 1 ). In addition to the SFRC specimen, a mesoscopic plain concrete and a macroscopic specimen are also investigated. Although some experimental and numerical research studies show that shape of coarse aggregate might affect the behavior of the concrete (e.g., [13,14]), but in order to avoid additional complexity of the problem, the aggregates of the specimens are assumed to be spherical. The diameter of coarse aggregates is assumed within the range of $4.76 \mathrm{~mm}$ to $11.2 \mathrm{~mm}$. The generated model complies with Fuller's grading curve depicted in Figure 2.

According to the numerical study of Hao and Hao [15], ITZ does not have a significant effect on the DIF of model; in addition, effect of ITZ on the stress and strain distribution of the model becomes less

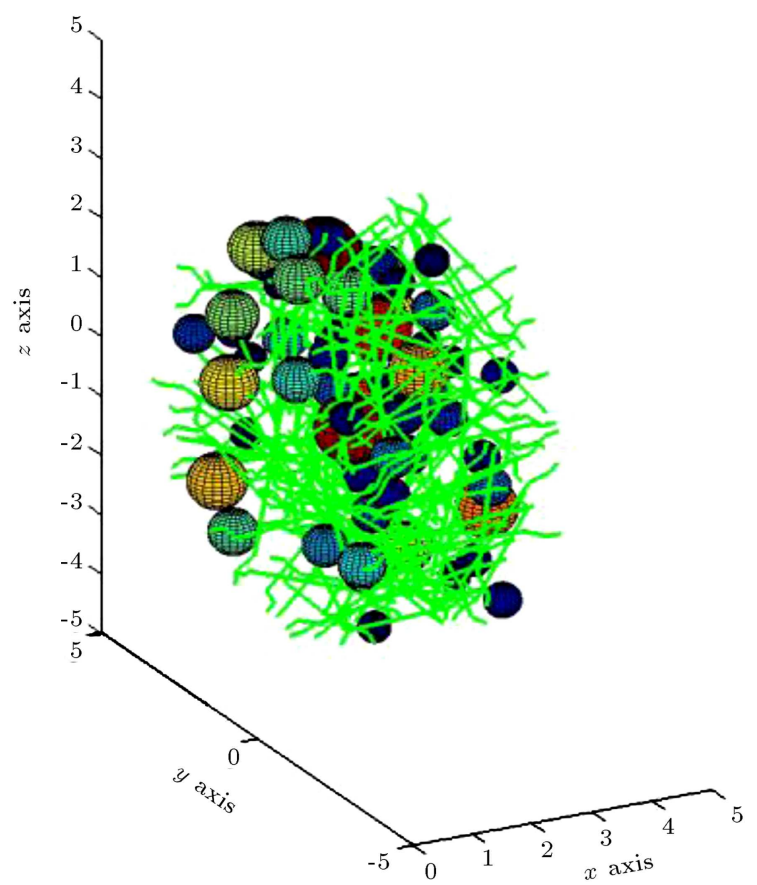

Figure 1. An instance of SFRC model generation.

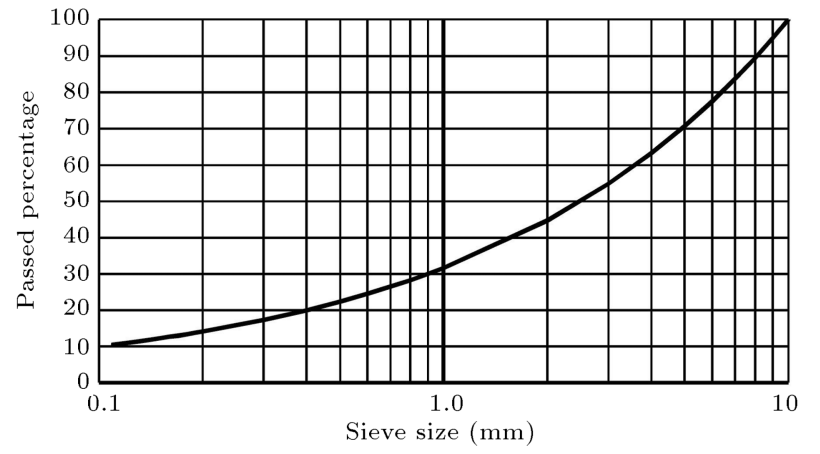

Figure 2. Fuller grading curve.

dominant as the strain rate increases from $10 \mathrm{~s}^{-1}$ to $100 \mathrm{~s}^{-1}$. Accordingly, in the current research, in order to reduce the complexity of the model, full bond is assumed between all of the phases of the model. Thus, the model is composed of three phases: aggregate, mortar, and steel fiber.

\section{Numerical simulation}

Mesoscopic steel fiber-reinforced concrete and mesoscopic plain concrete models, as well as a model solely consisted of a homogenous mortar phase (representing a macroscopic concrete model), are investigated at different strain rates. Specimens undergo the damage procedure in strain rate values of $10 \mathrm{~s}^{-1} 1,50 \mathrm{~s}^{-1}$, and $100 \mathrm{~s}^{-1}$ (Figure 3 ). Within this range of strain rate, the behavior of the model before and after reaching strain rate transition point (the strain rate at which the strength enhancement rapidly increases) will be obtained. (Some numerical research studies indicate strain rates higher than $100 \mathrm{~s}^{-1}$ as the transition point (e.g., [7]), but according to the experiments of Lok and Zhao [6], the transition strain rate is about $20 \mathrm{~s}^{-1}$ and according to the CEB-FIP[16] formulation, used

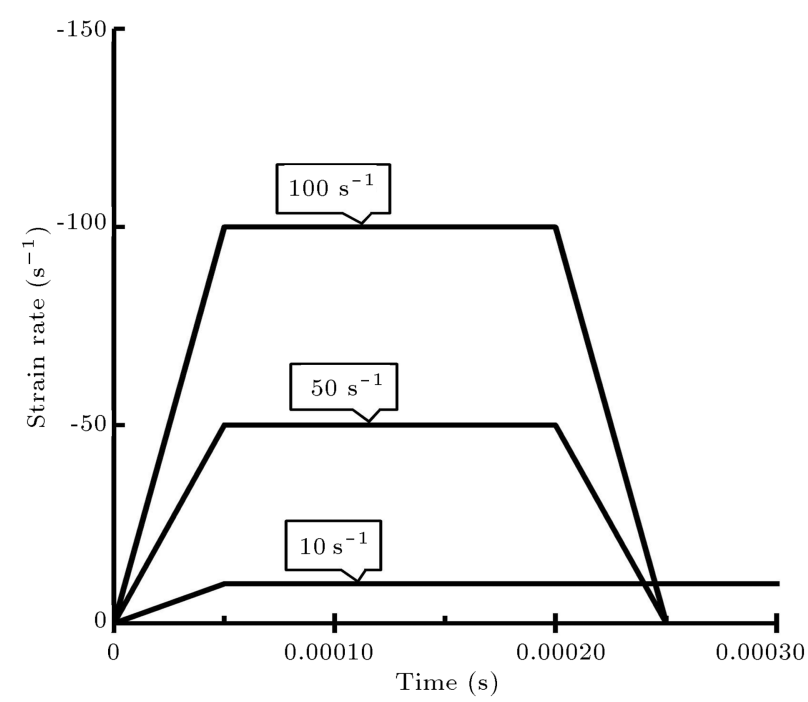

Figure 3. Loading strain rates. 


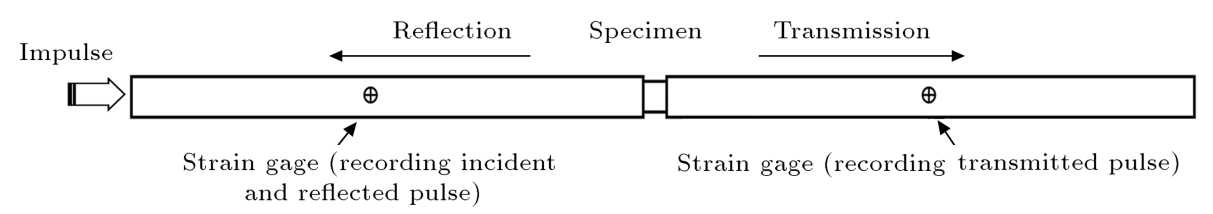

Figure 4. Kolsky apparatus of SHPB test.

in this study, the transition point is at strain rate of $30 \mathrm{~s}^{-1}$.) Ramp down to zero strain rate is excluded for strain rate of $10 \mathrm{~s}^{-1}$, allowing the model to complete its damage procedure. The average stress of each specimen and its strength are obtained from the results. In order to use Richardson extrapolation, this procedure is done for three different Average Element Lengths (AEL), namely fine $(0.478 \mathrm{~mm})$, medium $(0.620 \mathrm{~mm})$, and coarse elements $(0.794 \mathrm{~mm})$.

\subsection{Modeling assumptions and boundary conditions}

As shown in Figure 4, specimen of SHPB test is relatively a small part of the whole test set up. In the present research, to simulate this setup, the incident and transmit bars of the test have been omitted, and a velocity boundary condition has been directly applied to the faces of the specimen. In an SHPB test, producing a constant strain rate in specimen is ideal, and if it is achieved, it will usually have a trapezoid shape. To simulate such a situation for the produced model, a velocity boundary condition is applied to one face of the model, while the other face is prescribed with zero axial displacement (Figure 5(b)). Following that, the specimen will undergo increasing strain rate up to a specific peak value; afterwards, the strain rate remains constant until it reaches a ramp down to zero. This method of simulating the SHPB test is originally adopted from the previous works of $\mathrm{Ma}$ et al. [16] and Zhou and Hao [7]. The friction between specimen and bars of Kolsky apparatus can provide additional confinement to the specimen leading to misinterpretation of the test results. According to the simulation performed by $\mathrm{Li}$ and Meng [17], the effect of friction for a specimen with slenderness ration of 0.5 may be neglected if the friction coefficient is smaller than 0.1. This research assumes that this precaution is paid, and the end friction may be neglected.

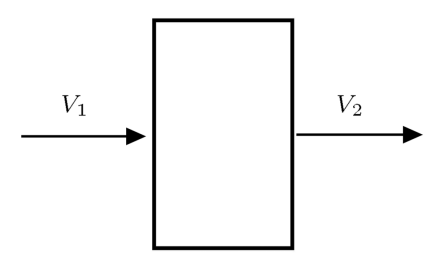

(a)

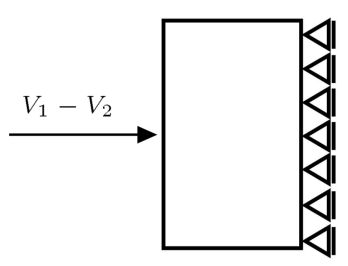

(b)
Figure 5. Boundary conditions: (a) Simplified boundary conditions for SHPB test, and (b) alternative boundary conditions.

\subsection{Dynamic increase factor formulation}

Dynamic Increase Factor (DIF) is the ratio of maximum strength of concrete under dynamic loading to its static strength. Dynamic increase factor is a function of strain rate. Since the strength of concrete increases with strain rate; thus, dynamic increase factor is expected to be equal to or greater than unity. By having DIF of a concrete specimen, it is possible to predict its strength under a dynamic loading with specific strain rate. The formulation recommended by CEB-FIP code [18] is one of the most commonly used formulas for calculating the dynamic increase factor of concrete. CEB-FIP formulation gives DIF of concrete as a function of static strength and strain rate. Malvar and Ross [19] proposed a modified formulation of CEB-FIP code that would better predict strength enhancement of concrete in tension (Figure 6). The DIF curves of concrete with different strength are depicted in Figure 7 . In this figure, CEB formulation

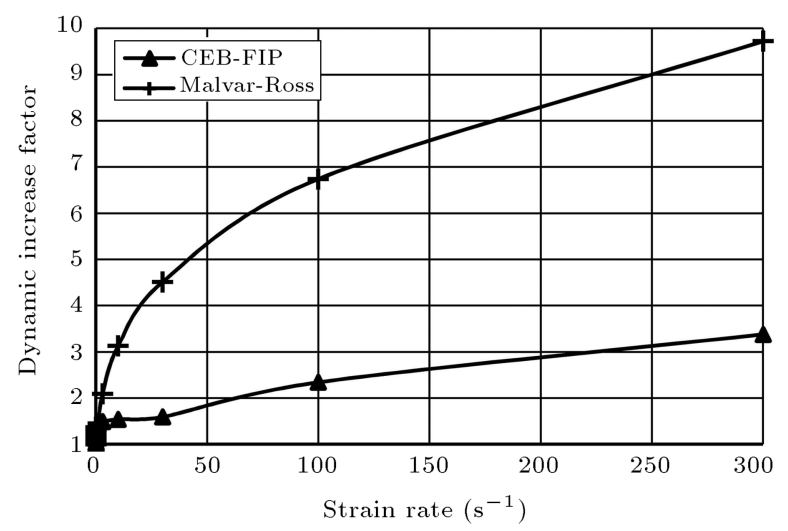

Figure 6. Comparison of Malvar-Ross formulation with recommendation of CEB-FIP for Tensile Dynamic Increase Factor (TDIF) of $45 \mathrm{MPa}$ concrete.

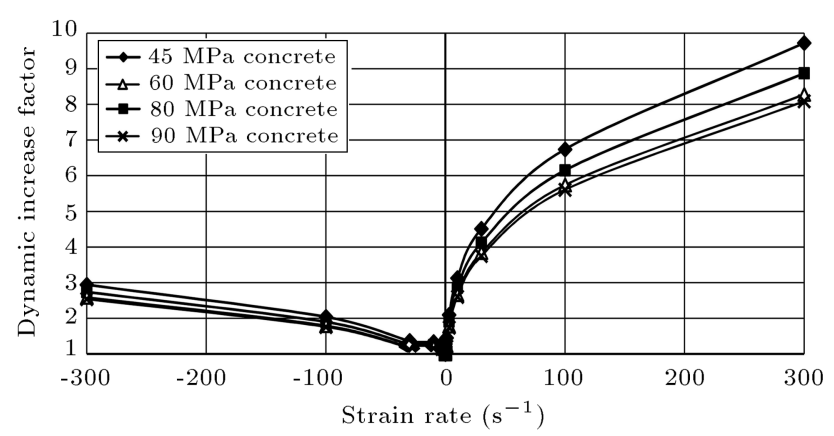

Figure 7. Dynamic increase factor curves for concretes with different strengths. 
is used to calculate the compressive dynamic increase factor, and the modified formulation of Malvar and Ross is used to calculate tensile dynamic increase factor. In this figure, negative values show compressive strain rates. (This sign convention does not necessarily comply with the convention of FEA packages; thus, extra care should be taken for defining DIF curves.) In many similar research studies (e.g., [12,20,21]), a DIF curve based on CEB-FIP [18] recommendation for compressive strength enhancement is applied to the mortar phase. Accordingly, the recommended DIF curve of $80 \mathrm{MPa}$ concrete demonstrated in Figure 7 is introduced to material model of mortar.

\subsection{Material models}

For each phase of mesoscopic model, an appropriate material model should be defined. For the structural properties of each phase of the model, the specimen used in the research of Lok and Zhao [6] is used as a reference. This will allow verification of the model behavior with the results of the experiment. Since the given detail on the specification of the specimen and its component is concise, reasonable assumptions are taken when precise properties are unknown.

\subsubsection{Steel fibers}

Constant stress hexahedral elements are used to model steel fibers. Structural properties of steel fibers are given in Table 1. The Piece-wise linear material model is applied to the elements of steel fibers. The effect of strain rate on steel fibers is ignored.

\subsubsection{Mortar matrix}

Mortar matrix comprises constant stress tetrahedral elements assigned with Karagozian-Case (K\&C) concrete damage material model. By improving pseudo tensor model, Malvar et al. [22] developed this model for simulating concrete walls under extreme loadings. $\mathrm{K} \& \mathrm{C}$ model has three strength surfaces in HaighWestergaard stress space. After reaching the initial yield surface, the stress increases in a hardening procedure until it reaches the maximum strength surface. After this point, the softening procedure starts until the material reaches the residual strength surface (Figure 8). Meridian curves of strength surfaces are defined according to Eq. (1) [22]:

$$
F(P)=a_{0}+\frac{P}{a_{1}+a_{2} P},
$$

Table 1. Mechanical specifications of steel fibers (RC-65/35-BN).

\begin{tabular}{ccc}
\hline No. & Parameter & Value \\
\hline 1 & Yield stress $(\mathrm{MPa})$ & 1345 \\
2 & Unit weight $\left(\mathrm{kg} / \mathrm{m}^{3}\right)$ & 7800 \\
3 & Poisson ratio & 0.3 \\
4 & Elastic modulus $(\mathrm{GPa})$ & 210 \\
\hline
\end{tabular}

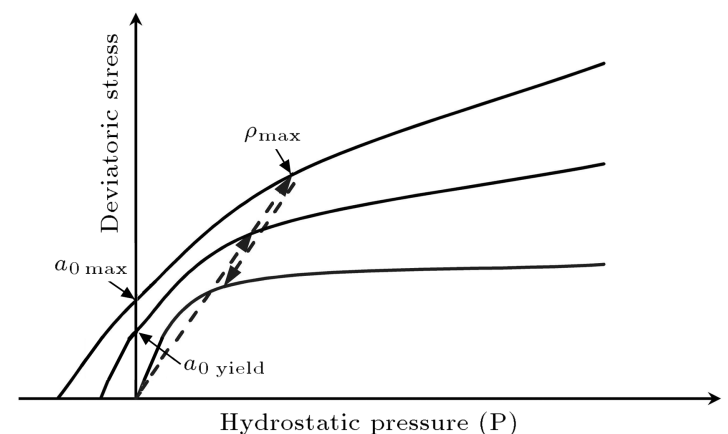

(a)

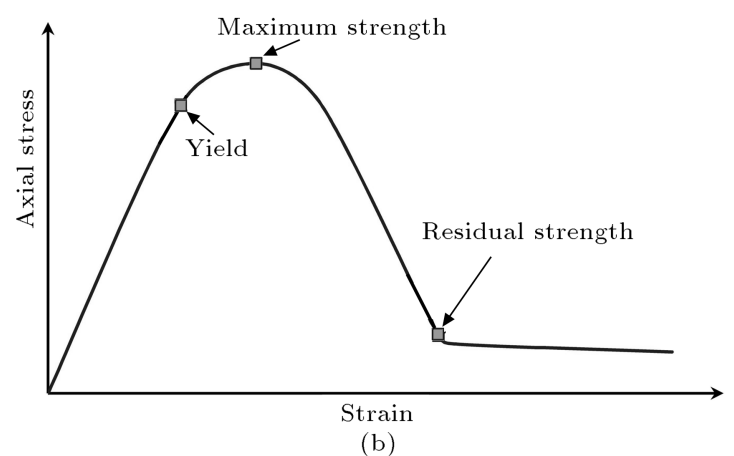

Figure 8. K\&C concrete damage material model: (a) meridians of strength surfaces, and (b) stress-strain curve.

where $P$ is hydrostatic pressure (representing volumetric stress), and $a_{0}, a_{1}$, and $a_{2}$ are constants that will be defined separately for each curve. Since the residual strength of the concrete is only due to imposed confinement in compressive loadings, $a_{0}$ factor for residual curve will be equal to zero causing the residual meridian to meet the origin. In the present research, the strength of the mortar matrix is assumed $80 \mathrm{MPa}$, Poisson ratio is taken equal to 0.2 and due to its high strength, the unit weight of $2700 \mathrm{~kg} / \mathrm{m}^{3}$ is considered.

The K\&C material model can accept a rate sensitivity (DIF) curve. The implemented DIF curve is discussed in Section 2.2.

In order to obtain deformation and damage process of the elements, authors used scaled damage measure. Scaled damage measure is a specific output for $\mathrm{K} \& \mathrm{C}$ material model defined by the following equation:

$$
\text { Scaled damage measure }=\frac{2 \lambda}{\lambda+\lambda_{m}},
$$

in which $\lambda$ is the modified effective plastic strain (damage function), and $\lambda_{m}$ is the modified effective plastic strain corresponding to the model maximum strength surface [22]. Scaled damage measure is thus equal to zero for intact elements and converges to 2 for damaged elements with large values of $\lambda$.

The input mechanical specifications of the mortar matrix are given in Table 2. 
Table 2. Mechanical specifications of mortar matrix.

\begin{tabular}{ccc}
\hline No. & Parameter & Value \\
\hline 1 & Compressive strength $(\mathrm{MPa})$ & 80 \\
2 & Tensile strength $(\mathrm{MPa})$ & 5.58 \\
3 & Unit weight $\left(\mathrm{kg} / \mathrm{m}^{3}\right)$ & 2700 \\
4 & Poisson ratio & 0.2 \\
\hline
\end{tabular}

\subsubsection{Aggregates}

Type of material assumed for the aggregates can affect the property of the model, e.g. for a high-strength specimen, aggregates might be made of high-strength granite or quartzite. While in each case, materials would have their own structural properties. Poisson ratio of granite will be about 0.3 that is higher than the Poisson ratio of 0.2 assumed for mortar matrix, while Poisson ratio of quartzite aggregates is expected to be less than 0.15 that will be less than Poisson ratio of mortar matrix. Since the investigation of aggregate properties is not currently the subject of this study, authors simply assume that the aggregates are made of quartzite, and assume that aggregates will not undergo any damage process; a simple elastic material model is assigned to the aggregate elements. Similar to the mortar phase, aggregates are composed of constant stress tetrahedral elements. Structural properties assigned to material model of aggregates are given in Table 3 .

\subsection{Calibration}

In order to obtain a more realistic behavior from the model, it may be necessary to adjust some of the parameters of the $\mathrm{K} \& \mathrm{C}$ model assigned to the mortar phase. This material model has three softening parameters: $b 1$ parameter, which is the first parameter, controls the behavior of the model in compression and its sensitivity to transverse confinement, while the other two parameters ( $b 2$ and $b 3$ ) control the softening under tension.

The default $b 1$ parameter is adjusted for the element size of $10 \mathrm{~cm}$ (4 in) which is too large for the present research and may lead to unrealistic ductile behavior of the model [23]. In order to detect a reasonable value for $b 1$, a model of standard cylindrical specimen $(15 \times 30 \mathrm{~cm})$ meshed with $10 \mathrm{~mm}$ hexahedral elements is investigated under Uniaxial Unconfined Compressive loading (UUC) and its stress-strain curve is compared to stress-strain curve for C80 grade concrete recommended by CEB-FIP code [18]. In order

Table 3. Mechanical specifications of aggregates.

\begin{tabular}{ccc}
\hline No. & Parameter & Value \\
\hline 1 & Elastic modulus $(\mathrm{MPa})$ & 82000 \\
2 & Unit weight $\left(\mathrm{kg} / \mathrm{m}^{3}\right)$ & 2800 \\
3 & Poisson ratio & 0.15 \\
\hline
\end{tabular}

to have a proper comparison, the numerical simulation should be conducted at a very low strain rate. However, this can lead to a very long analysis time. Considering that without a DIF curve, the K\&C material model cannot account for the influence of factors affecting the behavior of concrete at lower strain rates [24], it is expected that a good approximation of quasi-static strain rate can be obtained while avoiding the reduction of strain rate of simulation to a very low value. Based on this hypothesis, $b 1$ parameter is calibrated while the test is simulated at strain rates of $0.1 \mathrm{~s}^{-1}$ and $0.01 \mathrm{~s}^{-1}$. The obtained results show that for $b 1=$ 0.5 , the stress-strain curve of the model gives a good approximation of CEB-FIP stress-strain curve while reducing the strain rate from $0.1 \mathrm{~s}^{-1}$ to $0.01 \mathrm{~s}^{-1}$ had a minimal effect on the obtained results (Figure 9). Another factor that may impair the objectivity of this strategy is the mesh size dependency of $b 1$ parameter. In order to investigate the influence of mesh size on the obtained results, the same analysis is repeated with mesh size of $5 \mathrm{~mm}$. As depicted in Figure 9, reduction of mesh size had a little influence on the obtained results.

A summary of other damage evolution parameters and localization width is given in Table 4 . The default values of $b 2$ and $b 3$ are not changed, and localization width is taken equal to three times the maximum aggregate size of mortar, as recommended in [25,26].

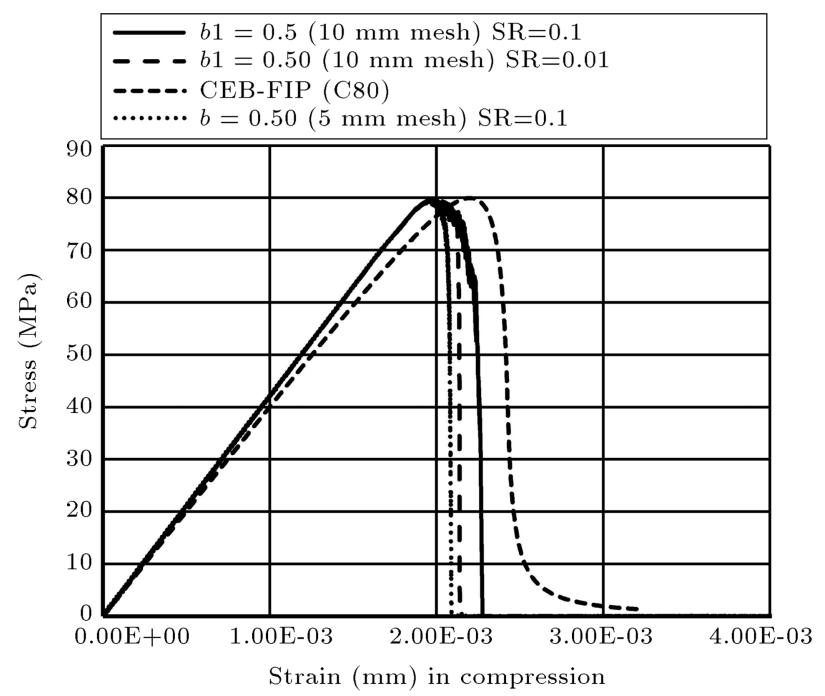

Figure 9. Calibration of $b 1$ Parameter.

Table 4. Damage evolution parameters of mortar material model.

\begin{tabular}{ccc}
\hline No. & Parameter & Value \\
\hline 1 & $b 1$ & 0.5 \\
2 & $b 2$ & 1.35 \\
3 & $b 3$ & 1.15 \\
4 & Localization width $(\mathrm{m})$ & 0.0142 \\
\hline
\end{tabular}




\subsection{Erosion criterion}

In order to visualize the damage imposed on the model, erosion algorithm was introduced to the model. Erosion algorithm will remove elements that pass specific defined criteria. In order to visualize the fracture and spallation process of concrete defined by $\mathrm{K} \& \mathrm{C}$ material model, researchers have commonly implemented this method [9,27]. Obtaining a more stable model is also a side benefit of defining erosion criterion. The erosion criterion is introduced to the model based on a trial and error procedure. Taking advantage of similar previous work of $\mathrm{Xu}$ et al. [9], initial values of 0.15 and 0.8 were, respectively, defined for the maximum principal strain and maximum shear strain at failure. It should be noticed that the elements that pass the mentioned criterion are completely damaged and will have a minor contribution to the strength response of the model. Obtained results confirm that with the mentioned values, effect of erosion criterion on stress response of the model is negligible.

\subsection{Discretization error}

It is recommended that accuracy of numerical methods and their uncertainties be estimated by a discretization error estimation method. In order to fulfill that goal, error bar is calculated based on the Grid Convergence Index (GCI) derived from Richardson Extrapolation (RE). RE method was first introduced by Richardson in early 20th century [28] and its application procedure is very well described in $[29,30]$. In order to verify results using RE method, the models were produced with three different Average Element edge Lengths (AEL) and the maximum strength of specimen was selected as the main output variable. By having main output variable for different AELs, it is possible to accordingly calculate Apparent Order of Convergence (AOC), Grid Convergence Index (GCI), and finally error bar length which is an approximation of the range that converged results will fall in.

\section{Results}

\subsection{Effect of steel fibers and aggregates for the models with DIF curve}

In this section, models are investigated while DIF curve is defined for $\mathrm{K} \& \mathrm{C}$ material model. A summary of obtained results is given in Table 5. By increasing the strain rate, although the strength of the specimens is increased due to dynamic enhancement effect, aggregates and steel fibers will not lead to a significant change in the strength enhancement of the model. At lower strain rates, the homogenous model has a marginally higher strength, while at higher strain rate, it falls below SFRC mesoscopic model.

\subsection{Effect of inertial confinement on the strength enhancement of the models}

In order to investigate the effect of confinement caused by inertia, the models were simulated without DIF curve. The obtained results are given in Table 6 . It can be observed that even without a DIF curve defined for the models, at higher strain rates, due to inertial confinement, the strength of the specimens noticeably increases. It is also observed that at lower strain rates, the strength of the compound converges to $80 \mathrm{MPa}$, which is equal to the strength defined for material model of the mortar. By taking $80 \mathrm{MPa}$ as static strength of the specimen, the ratio of strength enhancement is obtained.

A summary of the obtained results in this section is presented in Table 6 . According to the results, there is no dramatic difference between the obtained DIF curves of the Mesoscopic (steel fiber-reinforced and plain concrete) and the macroscopic (homogenous) specimen. In addition, it should be noted that for mesoscopic models at strain rate of 10 , a relatively big error is predicted by RE method; thus, the mentioned results are ignored.

\section{Discussion}

Obtained enhancement ratios of the models are depicted in Figure 10 along with the results obtained from some previous research studies, including Lok

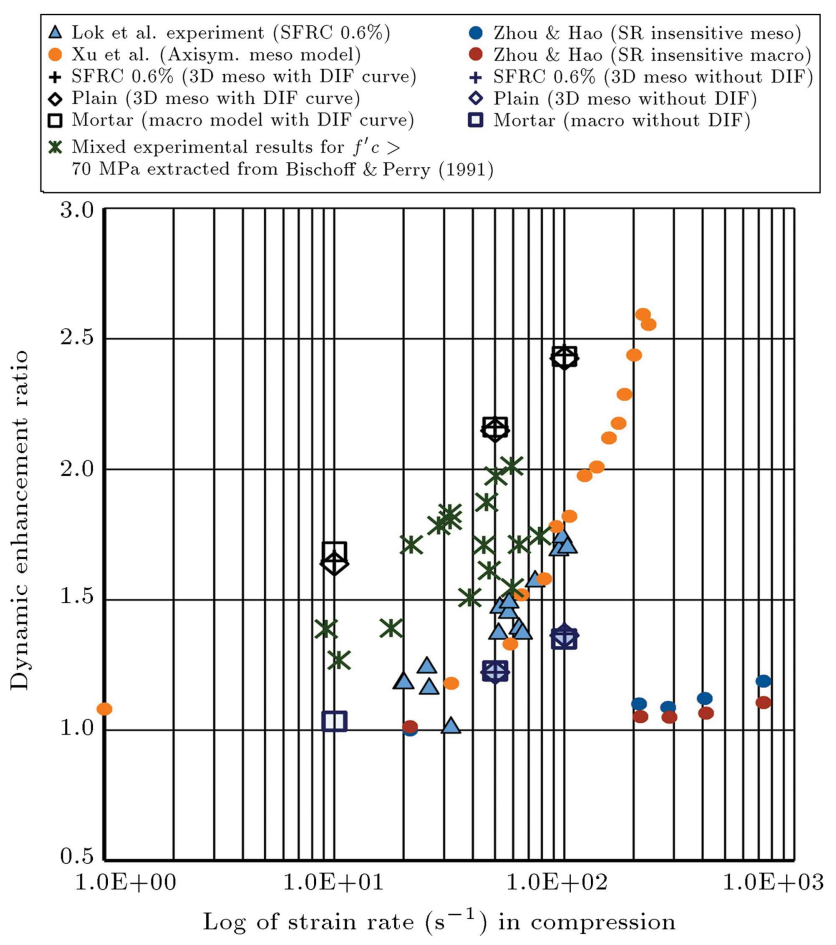

Figure 10. Strength of the model compared with experimental work of Lok and Zhao [6] and 2D axisymmetric mesoscopic model of Xu et al. [9]. 
Table 5. Calculation of discretization error using RE method for strain rate-sensitive models.

\begin{tabular}{|c|c|c|c|c|c|c|c|c|}
\hline No. & Specimen & $\begin{array}{c}\text { Strain rate } \\
\left(\mathrm{s}^{-1}\right)\end{array}$ & $\begin{array}{c}\text { AEL } \\
(\mathrm{mm})\end{array}$ & $\begin{array}{c}\text { Strength }\left(\sigma_{\max }\right) \\
(\mathrm{MPa})\end{array}$ & $\begin{array}{c}\text { AOC } \\
(\mathrm{P})\end{array}$ & $\begin{array}{c}\sigma_{\max }^{\text {ext }} \\
(\mathrm{MPa})\end{array}$ & GCI & $\begin{array}{c}\text { Error bar } \\
(\mathrm{MPa})\end{array}$ \\
\hline \multirow{3}{*}{1} & \multirow{3}{*}{ SFRC } & \multirow{3}{*}{100} & 0.478 & 194.99 & \multirow{3}{*}{7.484} & \multirow{3}{*}{195.15} & \multirow{3}{*}{0.001076} & \multirow{3}{*}{0.21} \\
\hline & & & 0.620 & 193.98 & & & & \\
\hline & & & 0.794 & 187.67 & & & & \\
\hline \multirow{3}{*}{2} & \multirow{3}{*}{ Plain (meso) } & \multirow{3}{*}{100} & 0.478 & 193.98 & \multirow{3}{*}{8.312} & \multirow{3}{*}{194.09} & \multirow{3}{*}{0.000698} & \multirow{3}{*}{0.135} \\
\hline & & & 0.620 & 193.15 & & & & \\
\hline & & & 0.794 & 186.73 & & & & \\
\hline \multirow{3}{*}{3} & \multirow{3}{*}{ Homo (macro) } & \multirow{3}{*}{100} & 0.478 & 194.60 & \multirow{3}{*}{8.993} & \multirow{3}{*}{194.70} & \multirow{3}{*}{0.000686} & \multirow{3}{*}{0.133} \\
\hline & & & 0.620 & 193.60 & & & & \\
\hline & & & 0.794 & 184.47 & & & & \\
\hline \multirow{3}{*}{4} & \multirow{3}{*}{ SFRC } & \multirow{3}{*}{50} & 0.478 & 172.90 & \multirow{3}{*}{7.752} & \multirow{3}{*}{173.04} & \multirow{3}{*}{0.001038} & \multirow{3}{*}{0.179} \\
\hline & & & 0.620 & 171.96 & & & & \\
\hline & & & 0.794 & 165.71 & & & & \\
\hline \multirow{3}{*}{5} & \multirow{3}{*}{ Plain (meso) } & \multirow{3}{*}{50} & 0.478 & 171.83 & & & & \\
\hline & & & 0.620 & 171.09 & 8.473 & 171.92 & 0.000669 & 0.115 \\
\hline & & & 0.794 & 165.15 & & & & \\
\hline & & & 0.478 & 172.91 & & & & \\
\hline 6 & Homo (macro) & 50 & 0.620 & 171.99 & 7.783 & 173.04 & 0.001004 & 0.174 \\
\hline & & & 0.794 & 165.83 & & & & \\
\hline & & & 0.478 & 131.95 & & & & \\
\hline 7 & SFRC & 10 & 0.620 & 131.06 & 11.035 & 132.00 & 0.000507 & 0.067 \\
\hline & & & 0.794 & 117.52 & & & & \\
\hline & & & 0.478 & 130.99 & & & & \\
\hline 8 & Plain (meso) & 10 & 0.620 & 130.19 & 10.873 & 131.04 & 0.000478 & 0.063 \\
\hline & & & 0.794 & 118.55 & & & & \\
\hline & & & 0.478 & 134.72 & & & & \\
\hline 9 & Homo (macro) & 10 & 0.620 & 133.99 & 11.535 & 134.75 & 0.000355 & 0.048 \\
\hline & & & 0.794 & 121.42 & & & & \\
\hline
\end{tabular}

Note: The SFRC, Plain (Meso), and Homo (macro) phrases, respectively, indicate the steel fiber-reinforced concrete models, mesoscopic plain concrete models, and homogenous mortar models indicated in Section 2.

and Zhao's experiment [6], the meso-scale axisymmetric simulation by Xu et al. [9], Zhou and Hao's investigations on homogenous and mesoscopic finite element model indicating the contribution of inertial confinement [7], and finally various experimental results extracted from [2].

By comparing the strength enhancement of the models without DIF curve with the rate-insensitive models of Zhou and Hao (Figure 10), it can be concluded that unlike the results obtained by Zhou and Hao, the models created in the present research have considerable strength enhancement ratios for strain rates of $50 \mathrm{~s}^{-1}$ and $100 \mathrm{~s}^{-1}$.

In Figure 11, the obtained results are depicted along with the CEB-FIP code's recommended DIF curve [18] which divides the diagram into two regions $\mathrm{A}$ and $\mathrm{B}$. In region $\mathrm{A}$, there are enhancement ratios extracted from the models that have CEB-FIP's DIF curve defined for the rate sensitivity. Below the CEBFIP curve (region B), there are the results obtained from rate-insensitive models that gain their rate sensitivity solely from inertial confinement effect. None of 
Table 6. Calculation of discretization error using RE method for strain rate-insensitive models.

\begin{tabular}{|c|c|c|c|c|c|c|c|c|}
\hline No. & Specimen & $\begin{array}{l}\text { Strain rate } \\
\qquad\left(\mathrm{s}^{-1}\right)\end{array}$ & $\begin{array}{l}\text { AEL } \\
(\mathrm{mm})\end{array}$ & $\begin{array}{c}\text { Strength }\left(\sigma_{\max }\right) \\
(\mathrm{MPa})\end{array}$ & $\begin{array}{c}\mathrm{AOC} \\
(\mathrm{P})\end{array}$ & $\begin{array}{c}\sigma_{\max }^{\text {ext }} \\
(\mathrm{MPa})\end{array}$ & GCI & $\begin{array}{c}\text { Error bar } \\
(\mathrm{MPa})\end{array}$ \\
\hline \multirow{3}{*}{1} & \multirow{3}{*}{ SFRC } & \multirow{3}{*}{100} & 0.478 & 109.61 & \multirow{3}{*}{1.775} & \multirow{3}{*}{109.21} & \multirow{3}{*}{0.00458} & \multirow{3}{*}{0.502} \\
\hline & & & 0.620 & 109.85 & & & & \\
\hline & & & 0.794 & 110.20 & & & & \\
\hline \multirow{3}{*}{2} & \multirow{3}{*}{ Plain (meso) } & \multirow{3}{*}{100} & 0.478 & 109.11 & \multirow{3}{*}{3.327} & \multirow{3}{*}{108.95} & \multirow{3}{*}{0.00180} & \multirow{3}{*}{0.197} \\
\hline & & & 0.620 & 109.33 & & & & \\
\hline & & & 0.794 & 109.81 & & & & \\
\hline \multirow{3}{*}{3} & \multirow{3}{*}{ Homo (macro) } & \multirow{3}{*}{100} & 0.478 & 107.93 & \multirow{3}{*}{0.727} & \multirow{3}{*}{107.63} & \multirow{3}{*}{0.00354} & \multirow{3}{*}{0.382} \\
\hline & & & 0.620 & 107.99 & & & & \\
\hline & & & 0.794 & 108.04 & & & & \\
\hline \multirow{3}{*}{4} & \multirow{3}{*}{ SFRC } & \multirow{3}{*}{50} & 0.478 & 97.82 & \multirow{3}{*}{2.207} & \multirow{3}{*}{97.53} & \multirow{3}{*}{0.00364} & \multirow{3}{*}{0.356} \\
\hline & & & 0.620 & 98.04 & & & & \\
\hline & & & 0.794 & 98.40 & & & & \\
\hline \multirow{3}{*}{5} & \multirow{3}{*}{ Plain (meso) } & \multirow{3}{*}{50} & 0.478 & 97.76 & & & & \\
\hline & & & 0.620 & 97.97 & 2.256 & 97.50 & 0.00332 & 0.325 \\
\hline & & & 0.794 & 98.32 & & & & \\
\hline & & & 0.478 & 98.21 & & & & \\
\hline 6 & Homo (macro) & 50 & 0.620 & 98.35 & 1.435 & 97.92 & 0.00302 & 0.370 \\
\hline & & & 0.794 & 98.44 & & & & \\
\hline & & & 0.478 & 81.46 & & & & \\
\hline 7 & SFRC & 10 & 0.620 & 81.80 & 0.094 & 67.91 & 0.20802 & 16.946 \\
\hline & & & 0.794 & 82.11 & & & & \\
\hline & & & 0.478 & 81.52 & & & & \\
\hline 8 & Plain (meso) & 10 & 0.620 & 81.86 & 0.210 & 75.50 & 0.09223 & 7.518 \\
\hline & & & 0.794 & 83.20 & & & & \\
\hline & & & 0.478 & 82.75 & & & & \\
\hline 9 & Homo (macro) & 10 & 0.620 & 83.06 & 3.972 & 82.57 & 0.00261 & 0.216 \\
\hline & & & 0.794 & 83.16 & & & & \\
\hline
\end{tabular}

the regions correlates with the CEB-FIP recommendation. In the former region, the models overestimate the rate effect since the inertial confinement will contribute twice to the strength enhancement of the model by defining DIF curve. On the other hand, in region $\mathrm{B}$, the strength enhancement is underestimated by only having the inertial confinement to account for the strength enhancement of the model. In addition, by comparing the homogenous model with SFRC and plain concrete mesoscopic models, it can be concluded that steel fiber and aggregate have not dramatically affected the peak strength and dynamic strength ratio of the models.

Axial stress responses of the models are depicted in Figure 12. According to the depicted results, due to the stress concentration, especially at lower strain rates, meso-scale models will fail before macro-scale specimen. In addition, it can be observed that steel fibers have a negligible effect on the stress curve and only marginally increase the residual strength of the specimen. Distributions of axial stress and scaled damage measure of elements (the closest available contours at the time, which the model is in its strength peak) are depicted in Figures 13 to 18. In the mentioned figures, the pattern of stress and scaled damage measure on surface and cross section of the mesoscopic models are very much similar, and the irregular distribution of stress is apparent whilst for the macroscopic model 


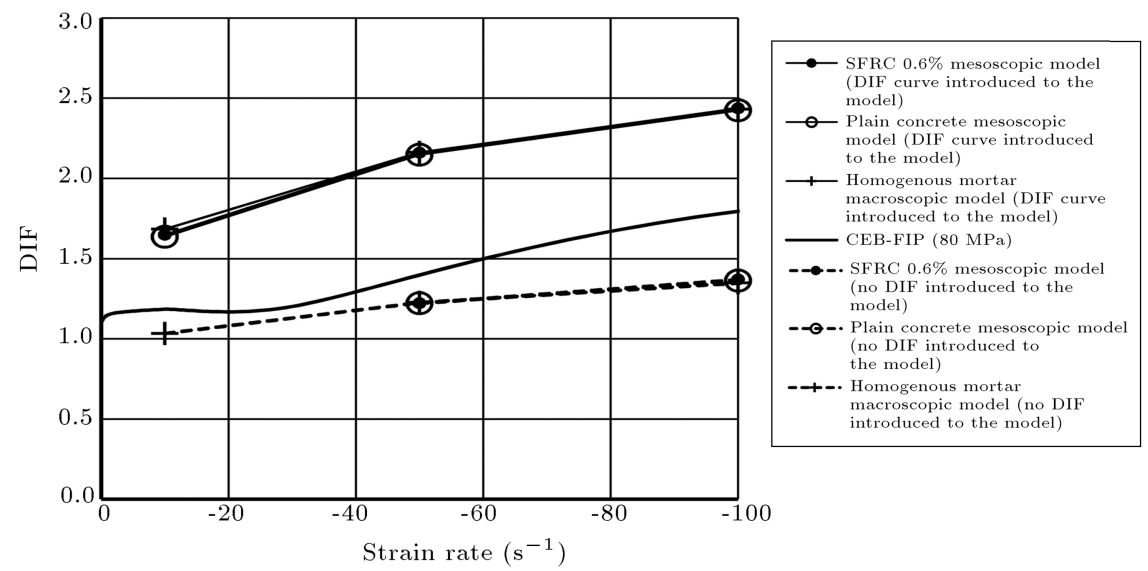

Figure 11. Strength enhancement ratios compared with defined DIF curve.

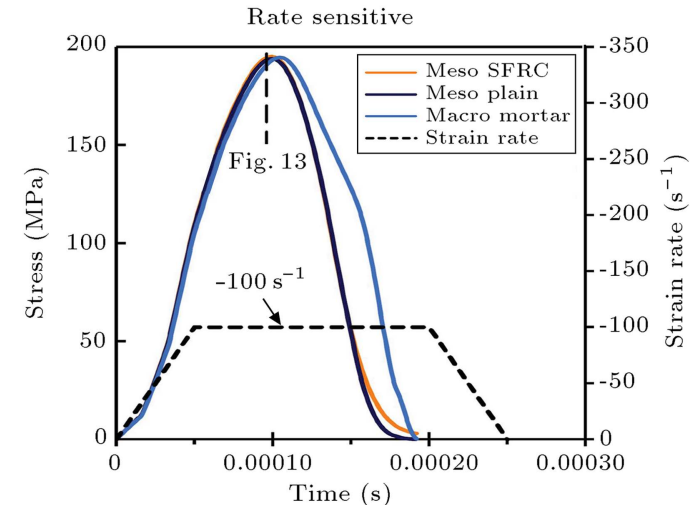

(a)

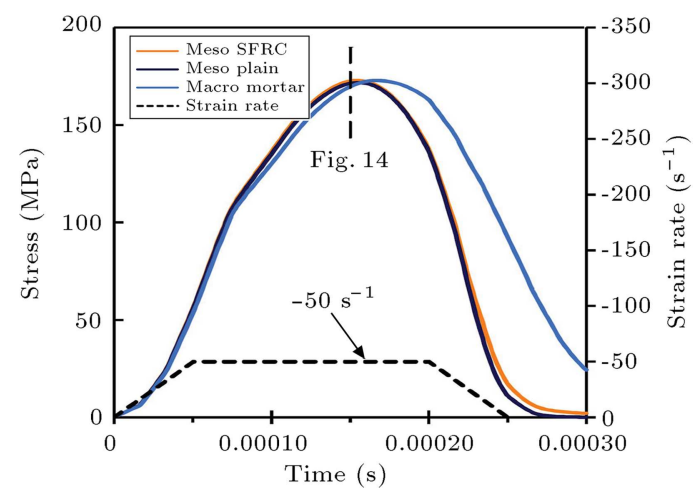

(c)

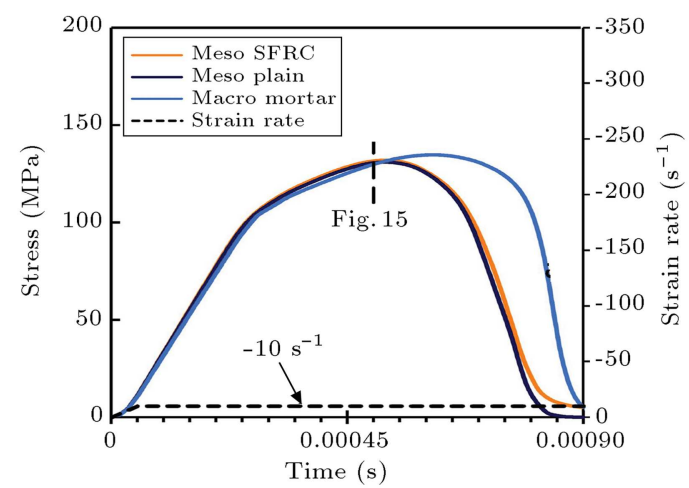

(e)

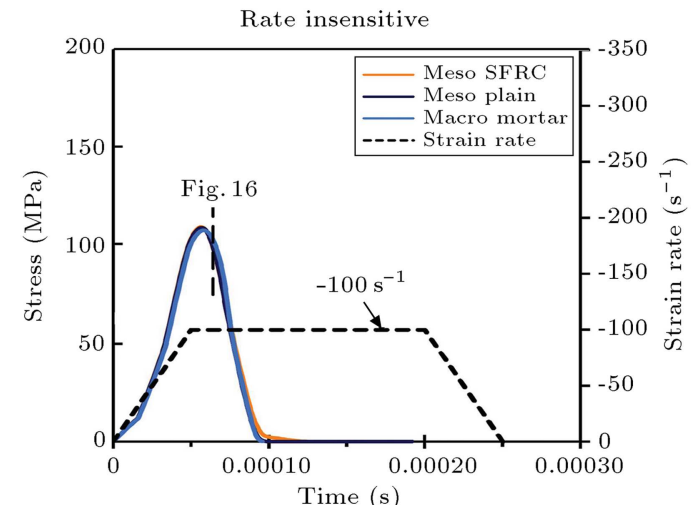

(b)

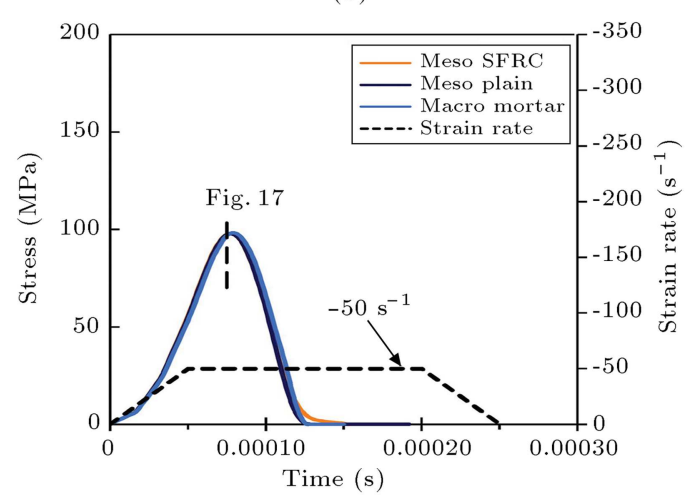

(d)

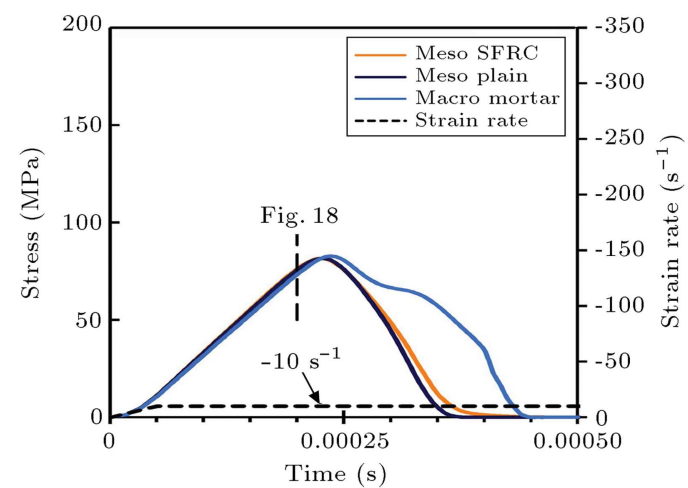

(f)

Figure 12. Stress response for rate sensitive ((a), (c), and (d)) and rate insensitive ((b), (d), and (f)) models. 


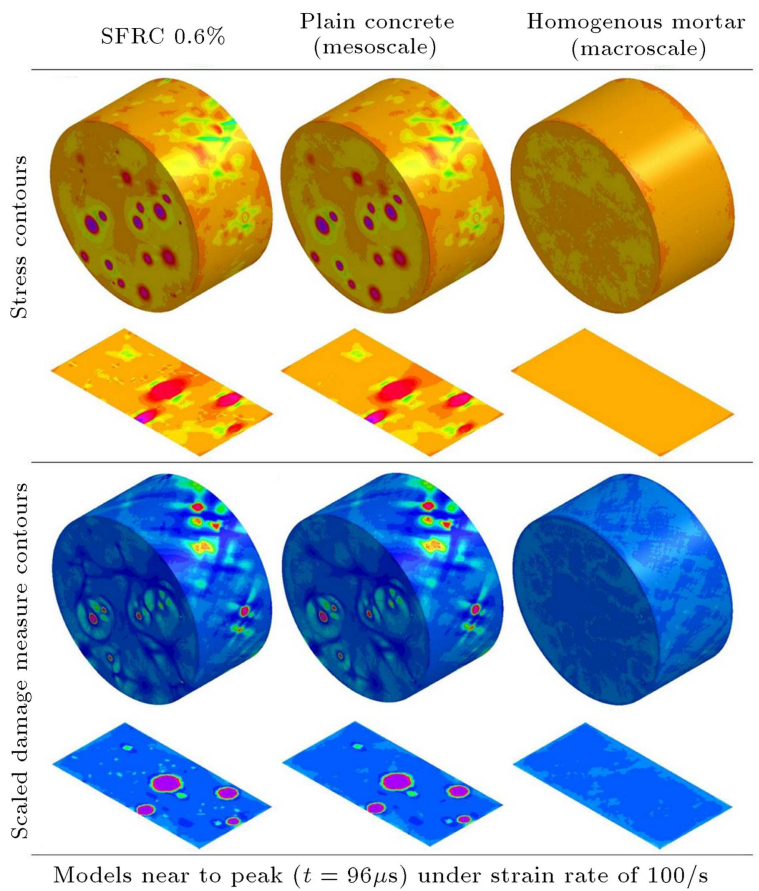

\begin{tabular}{ccccccc} 
Tension & \multicolumn{3}{c}{ Stress } & \multicolumn{2}{c}{ Compression } \\
70 & 0 & 70 & 140 & 210 & 280 & 350 \\
$\mathrm{MPa}$ & $\mathrm{MPa}$ & $\mathrm{MPa}$ & $\mathrm{MPa}$ & $\mathrm{MPa}$ & $\mathrm{MPa}$ & $\mathrm{MPa}$ \\
\hline Damaged & \multicolumn{3}{c}{ Scaled damage measure } & & Intact
\end{tabular}

Figure 13. Near to peak stress and scaled damage measure destribution for rate-sensitive model in strain rate of $100 \mathrm{~s}^{-1}$.

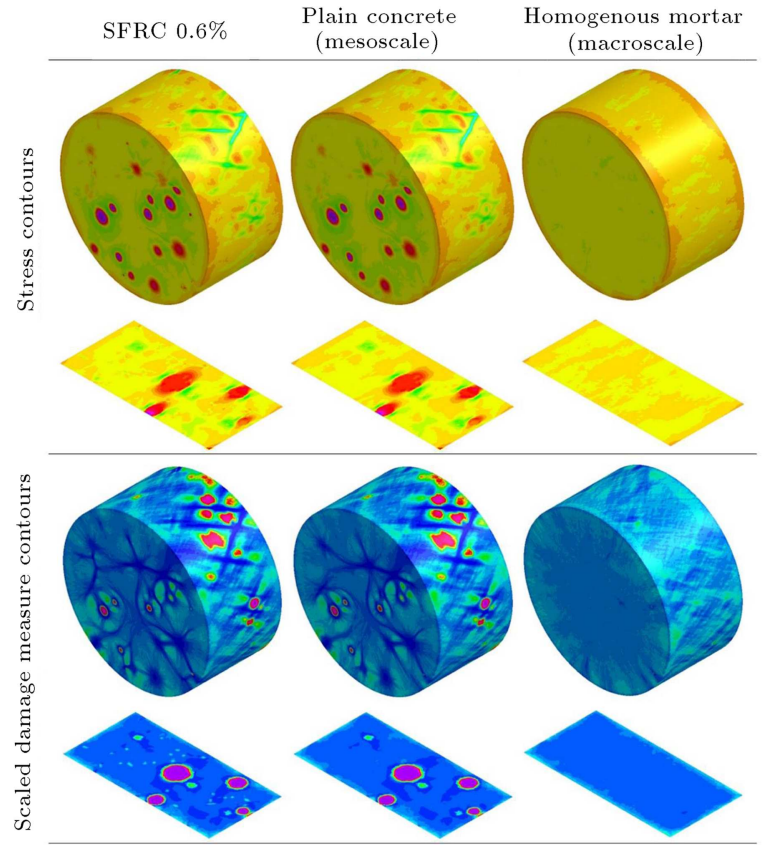

Models near to peak $(t=150 \mu \mathrm{s})$ under strain rate of $50 / \mathrm{s}$

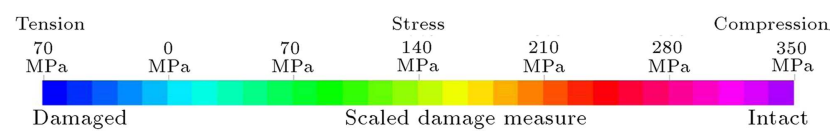

Figure 14. Near to peak stress and scaled damage measure distribution for rate-sensitive model in strain rate of $50 \mathrm{~s}^{-1}$.

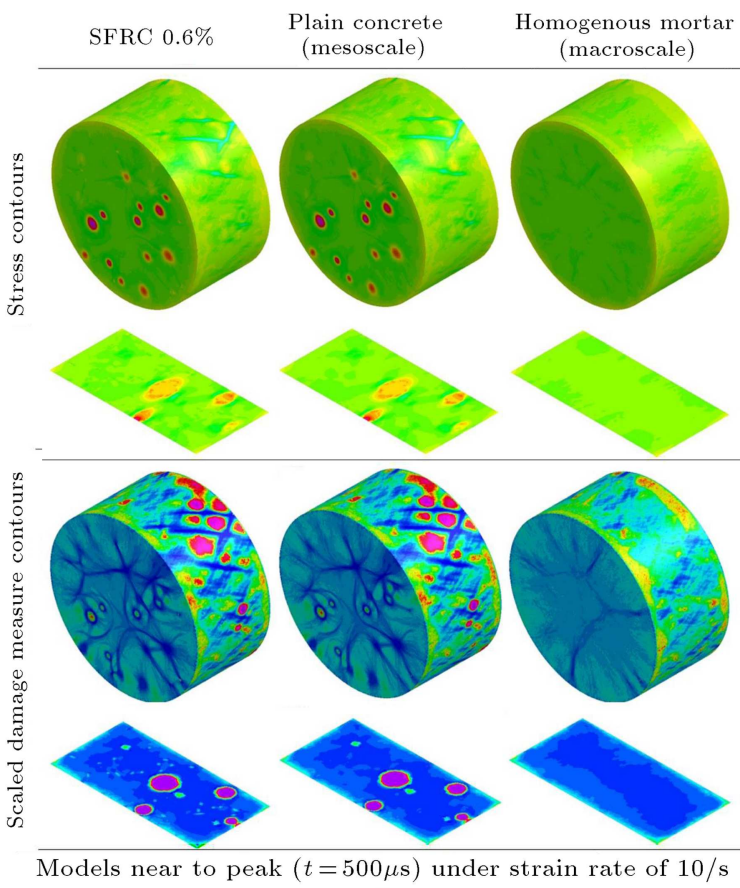

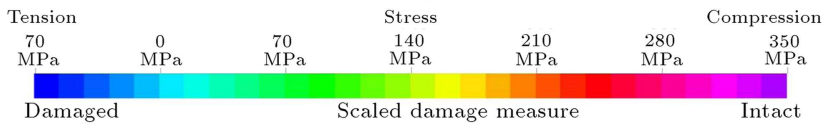

Figure 15. Near to peak stress and scaled damage measure distribution for rate-sensitive model in strain rate of $10 \mathrm{~s}^{-1}$.

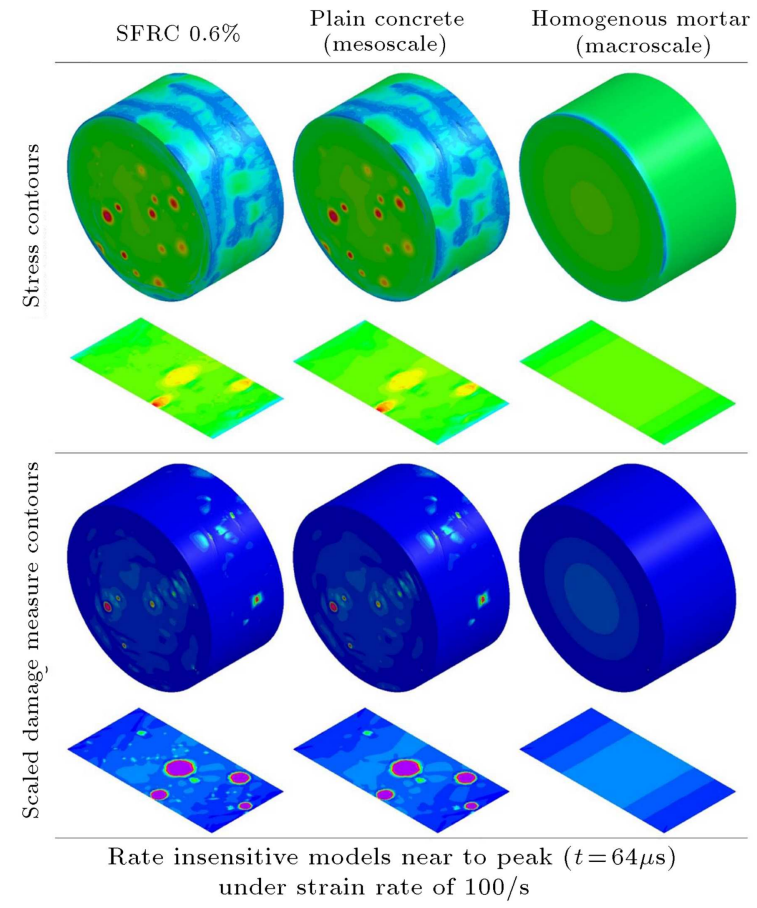

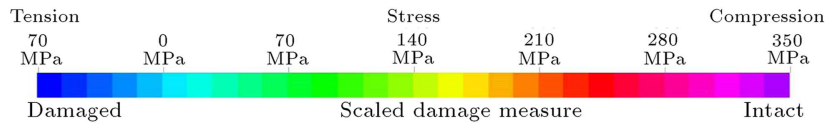

Figure 16. Near to peak stress and scaled damage measure distribution for rate-insensitive model in strain rate of $100 \mathrm{~s}^{-1}$. 


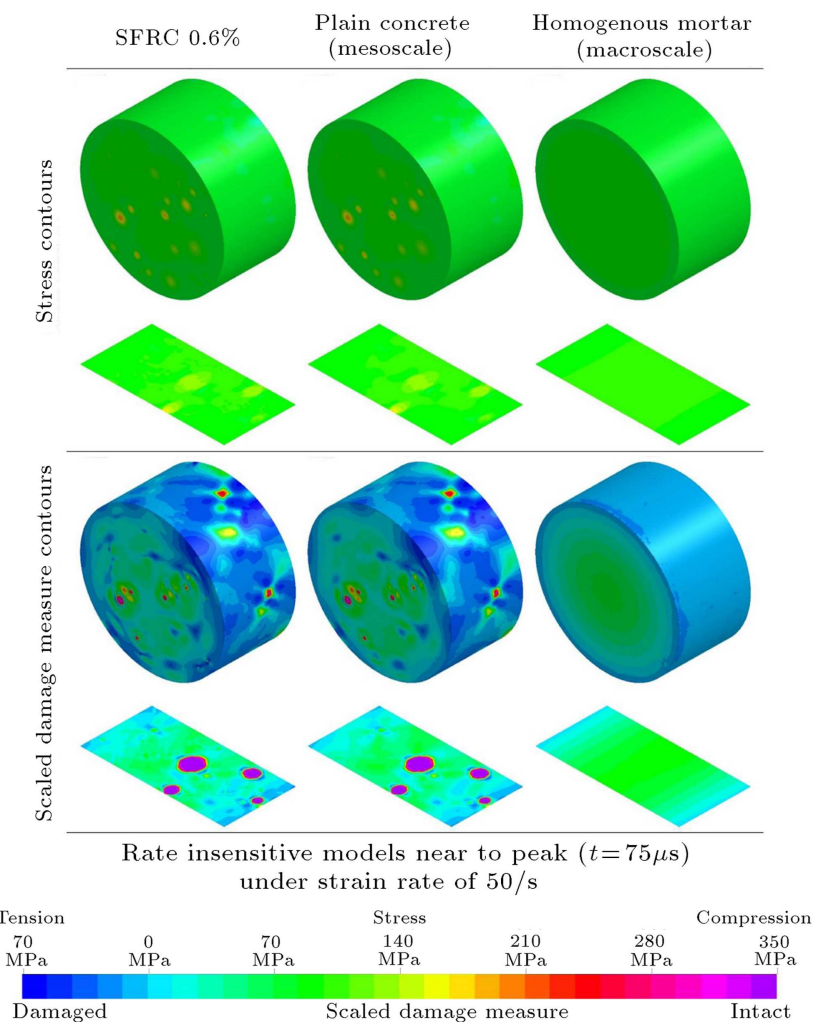

Figure 17. Near to peak stress and scaled damage measure distribution for rate-insensitive model in strain rate of $50 \mathrm{~s}^{-1}$.

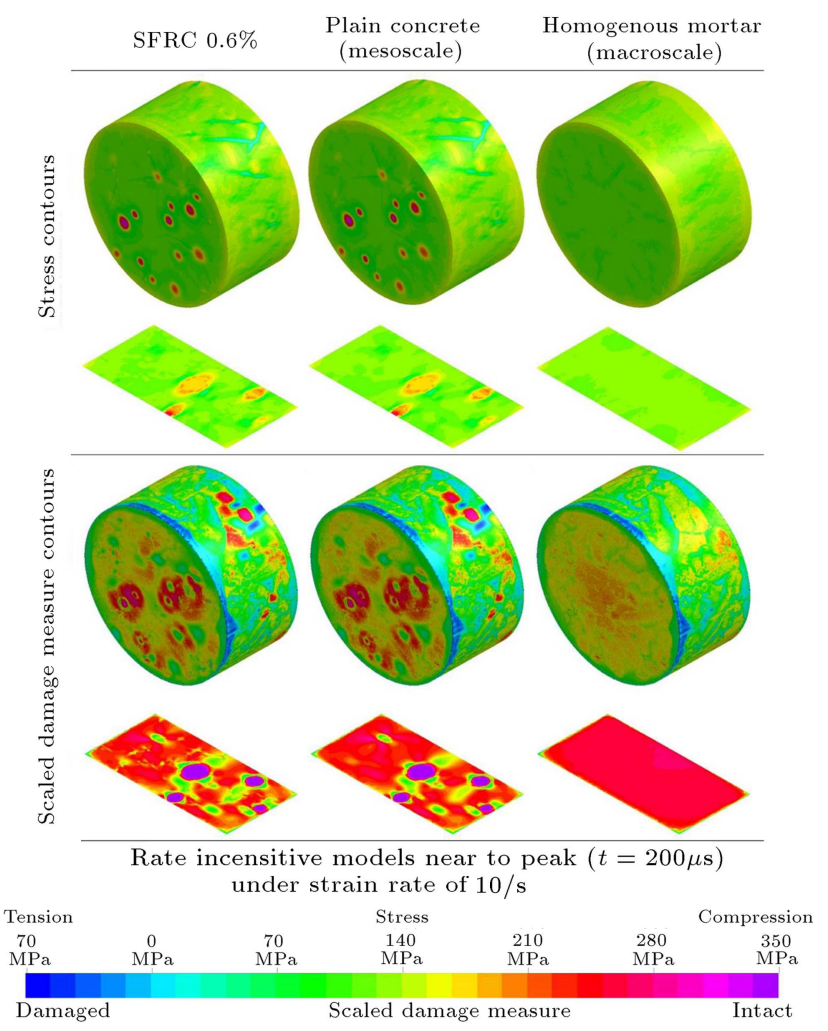

Figure 18. Near to peak stress and scaled damage measure distribution for rate-sinsensitive model in strain rate of $10 \mathrm{~s}^{-1}$.

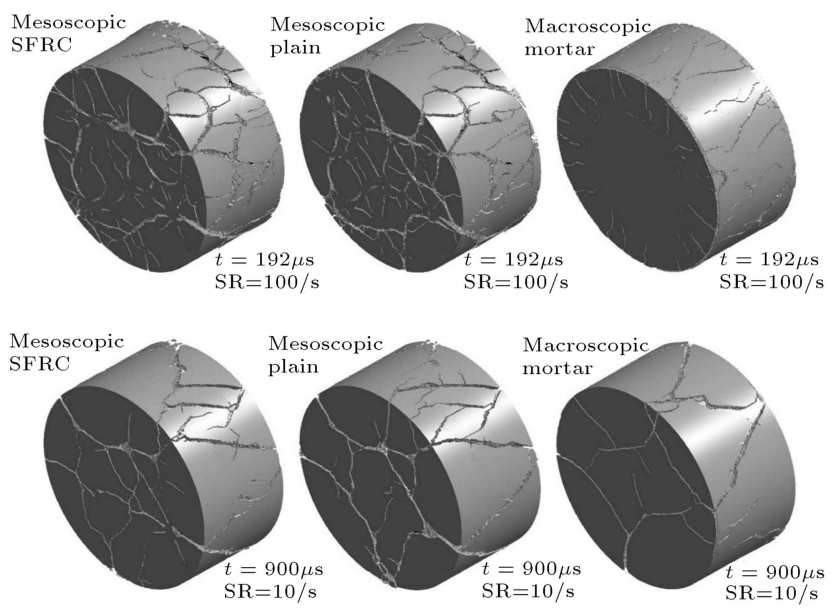

Figure 19. Rate sensitive damaged models.
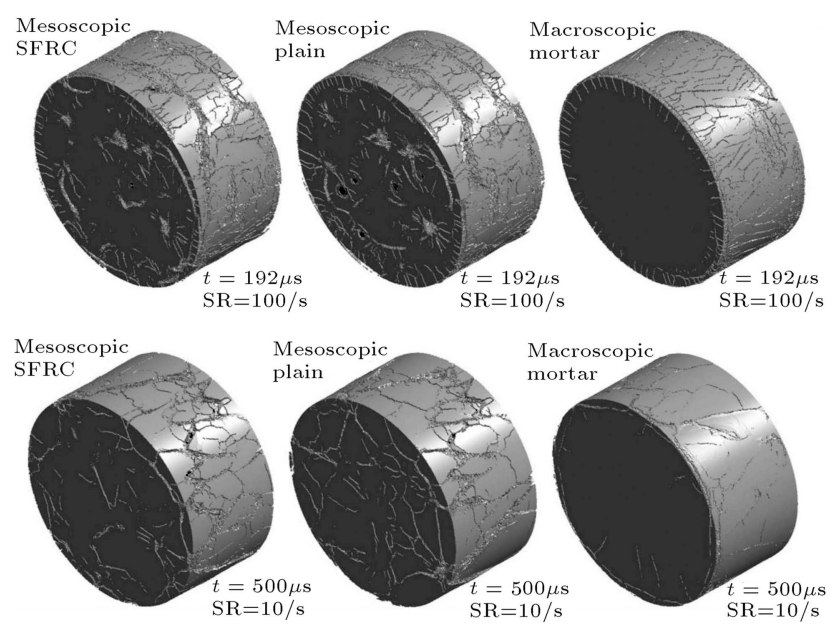

Figure 20. Rate insensitive damaged models.

(homogenous mortar), a more uniform distribution of stress is observed.

Finally, in Figures 19 and 20, damaged models are depicted. According to these figures, compared to meso-scale models, the homogenous macro-scale models have undergone less damage whilst it does not seem that steel fibers have had a dramatic effect on the damaged shape of the meso-scale specimen. At strain rate of $10 \mathrm{~s}^{-1}$, rate-sensitive model ruptures into several large fragments by a few wide cracks; however, at strain rate of $100 \mathrm{~s}^{-1}$, many fine cracks for both rate-sensitive and rate-insensitive models dominate the specimens' failure. According to the obtained results, the steel fibers had a negligible effect on the behavior of the current mesoscopic model; even at strain rate of $10 \mathrm{~s}^{-1}$, the model fails to capture the effect of steel fibers on the post-peak behavior of the specimen.

\section{Conclusion}

The research presented in this paper attempted to investigate the behavior of a mesoscopic finite ele- 
ment model of High-Strength Steel Fiber-Reinforced Cconcrete (HSSFRC) at high strain rates. Primarily, a computer code was developed to produce a threedimensional mesoscopic model for a concrete specimen reinforced with $0.6 \%$ volume fraction of hooked steel fiber with random distribution of aggregates and fibers. The strengths obtained from mesoscopic model at different strain rates were compared with the ones obtained from plain mesoscopic and homogenous mortar models. All the models were tested with and without dynamic strength increase factor (DIF) curves, introduced to the mortar phase.

Although inertial confinement had caused noticeable strength enhancement for the rate-insensitive models, yet the ratio of strength enhancement was not sufficient to comply with experimental results. On the other hand, while implementing a DIF curve into concrete material models is a common method to consider rate sensitivity, the results obtained in the current research showed how this might lead to overestimated results due to summation of the effect of inertial confinement with the implemented DIF curve.

The investigation was performed to estimate the element size sensitivity, which shows that for the models with DIF curve, the rate sensitivity was amplified as the average element edge length was reduced, while this increase in the strength enhancement ratio was not observed for rate-insensitive models.

According to the obtained average stresses, compared to macroscopic model, the failure process was accelerated in mesoscopic models. This effect diminished at very high strain rates. Steel fibers only had a marginal effect on the average stress response of the models. In addition, reinforced and non-reinforced mesoscopic models showed similar non-uniform distribution of stress and element damages, while the macroscopic model had less irregular distribution of stress and damage among elements.

Models' damage, which was visualized by taking advantage of element erosion criterion, showed that mesoscopic models had undergone more damage compared to the homogenous macroscopic model. In addition, for lower strain rate, the damaged specimens had a few wide cracks; while at higher strain rate, many fine cracks were formed.

\section{References}

1. Bischoff, P.H. and Perry, S.H. "Compressive strain rate effects of concrete", Cem.-Based Compos. Strain Rate Eff. Fract., 64, pp. 151-165 (1986).

2. Bischoff, P.H. and Perry, S.H. "Compressive behaviour of concrete at high strain rates", Mater. Struct., 24(6), pp. 425-450 (1991).

3. Harsh, S., Shen, Z. and Darwin, D. "Strain-rate sensitive behavior of cement paste and mortar in compression", ACI Mater. J., 87(5), pp. 508-516 (1990).

4. Le Nard, H. and Bailly, P. "Dynamic behaviour of concrete: the structural effects on compressive strength increase", Mech. Cohesive-Frict. Mater., 5(6), pp. 491$510(2000)$.

5. Lok, T.S., Zhao, P.J. and Lu, G. "Using the split Hopkinson pressure bar to investigate the dynamic behaviour of SFRC", Mag. Concr. Res., 55(2), pp. 183-191 (2003).

6. Lok, T.S. and Zhao, P.J. "Impact response of steel fiber-reinforced concrete using a split Hopkinson pressure bar", J. Mater. Civ. Eng., 16(1), pp. 54-59 (2004).

7. Zhou, X.Q. and Hao, H. "Modelling of compressive behaviour of concrete-like materials at high strain rate", Int. J. Solids Struct., 45(17), pp. 4648-4661 (2008).

8. Kim, D.J., Sirijaroonchai, K., El-Tawil, S. and Naaman, A.E. "Numerical simulation of the split hopkinson pressure bar test technique for concrete under compression", Int. J. Impact Eng., 37(2), pp. 141-149 (2010).

9. Xu, Z., Hao, H. and Li, H.N. "Mesoscale modelling of fibre reinforced concrete material under compressive impact loading", Constr. Build. Mater., 26(1), pp. 274-288 (2012).

10. Fang, Q. and Zhang, J. "Three-dimensional modelling of steel fiber reinforced concrete material under intense dynamic loading", Constr. Build. Mater., 44, pp. 118132 (2013).

11. Hao, Y., Hao, H., Jiang, G.P. and Zhou, Y. "Experimental confirmation of some factors influencing dynamic concrete compressive strengths in high-speed impact tests", Cem. Concr. Res., 52, pp. 63-70 (2013).

12. Xu, Z., Hao, H. and Li, H.N. "Mesoscale modelling of dynamic tensile behaviour of fibre reinforced concrete with spiral fibres", Cem. Concr. Res., 42(11), pp. 1475-1493 (2012).

13. Rocco, C.G. and Elices, M. "Effect of aggregate shape on the mechanical properties of a simple concrete", Eng. Fract. Mech., 76(2), pp. 286-298 (2009).

14. Kim, S.-M. and Al-Rub, R.K.A. "Meso-scale computational modeling of the plastic-damage response of cementitious composites", Cem. Concr. Res., 41(3), pp. 339-358 (2011).

15. Hao, Y. and Hao, H. "Numerical evaluation of the influence of aggregates on concrete compressive strength at high strain rate", Int. J. Prot. Struct., 2(2), pp. 177-206 (2011).

16. Ma, G.W., Wang, X.J. and Li, Q.M. "Modeling strain rate effect of heterogeneous materials using SPH method", Rock Mech. Rock Eng., 43(6), pp. 763-776 (2010).

17. Li, Q.M. and Meng, H. "About the dynamic strength enhancement of concrete-like materials in a split Hopkinson pressure bar test", Int. J. Solids Struct., 40(2), pp. 343-360 (2003). 
18. Europe-International Committee for Concrete CEBFIP Model, Code 1990: Design Code. The International Federation for Structural Concrete [Comite Euro-International du Beton CEB-FIP Model Code 1990: Design Code. fib Fédération internationale du béton] (1993).

19. Malvar, L.J. and Ross, C.A. "Review of strain rate effects for concrete in tension", ACI Mater. J., 95(6), pp. 735-739 (1998).

20. Zhou, X.Q. and Hao, H. "Mesoscale modelling and analysis of damage and fragmentation of concrete slab under contact detonation", Int. J. Impact Eng., 36(12), pp. 1315-1326 (2009).

21. Zhou, X.Q. and Hao, H. "Mesoscale modelling of concrete tensile failure mechanism at high strain rates", Comput. Struct., 86(21), pp. 2013-2026 (2008).

22. Malvar, L.J., Crawford, J.E., Wesevich, J.W. and Simons, D. "A plasticity concrete material model for DYNA3D”, Int. J. Impact Eng., 19(9), pp. 847-873 (1997).

23. Crawford, J.E., Wu, Y., Choi, H.J., Magallanes, J.M. and Lan, S. "Use and validation of the release III K\&C concrete material model in LS-DYNA", Karagozian 86 Case, Glendale, California, Technical Report (2012).

24. Magallanes, J.M., Wu, Y., Malvar, L.J. and Crawford, J.E. "Recent improvements to release III of the K\&C concrete model", 11th International LS-DYNA Users Conference, pp. 6-8 (2010).

25. Bazant, Z.P. and Cedolin, L., Stability of Structures: Elastic, Inelastic, Fracture and Damage Theories, World Scientific Publishing Company, Hackensack, NJ; London (2010).

26. LS-DYNA Keyword User's Manual, Livermore Software Technology Corporation (2012)

27. Xu, K. and Lu, Y. "Numerical simulation study of spallation in reinforced concrete plates subjected to blast loading", Comput. Struct., 84(5), pp. 431-438 (2006).

28. Richardson, L.F. "The approximate arithmetical solution by finite differences of physical problems involving differential equations, with an application to the stresses in a masonry dam", Philos. Trans. R. Soc. Lond. Ser. Contain. Pap. Math. Phys. Character, pp. 307-357 (1911).

29. Celik, I.B., Procedure for Estimation and Reporting of Discretization Error in CFD Applications, Mechanical and Aerospace Engineering Department West Virginia University, Morgantown WV (USA).

30. Schwer, L.E. "Estimating discretization error using GCI", LS-Dyna Anwenderforum, Bamberg (2008).

\section{Biographies}

Saeid Mehrpay He has attained his MSC degree in Structural Engineering from University of Guilan in 2014. His research was mainly regarding the numerical simulation of concrete and he is willing to continue his studies in this field further using Discrete Element Method.

Reza S. Jalali Graduated from University of Yazd in 1994 with a BSc Degree in Civil Engineering. $\mathrm{He}$ received his $\mathrm{MSc}$ and $\mathrm{PhD}$ degrees in Structural Engineering from Iran University of Science and Technology (IUST) in 1999 and 2007, respectively. He was a Doctoral Visiting Scholar at The University of Southern California (USC) during 2005-2006. He is currently an Assistant Professor at the Department of Civil Engineering, Faculty of Engineering, University of Guilan, Rasht, Iran. He has published in the areas of structural and earthquake engineering. 